\title{
Book Review: Modern Psychometrics With R
}

\author{
Alexander Robitzsch ${ }^{1,2 *}$ \\ ${ }^{1}$ IPN - Leibniz Institute for Science and Mathematics Education, Kiel, Germany, ${ }^{2}$ Centre for International Student \\ Assessment (ZIB), Kiel, Germany
}

Keywords: psychometrics, R, classical test theory, structural equating modeling, item response modeling

\begin{abstract}
A Book Review on
Modern Psychometrics With R

Patrick Mair (Cham: Springer), 2018, 458 pages, ISBN: 9783319931777

The book "Modern Psychometrics with R" by Patrick Mair provides extensive information about recent R (R Core Team, 2020) implementations of psychometric models. The book follows a broad definition of psychometrics in order to meet "the statistical needs of modern measurement" and exceeds the standard definition of psychological measurement (Mair, 2018, p. v). The author admits that several uncommon topics are included in the book, and the strength of the book is in its discussion of a broad range of $\mathrm{R}$ packages. The author has extensive expertise in the $\mathrm{R}$ community of psychometrics and is the maintainer of the CRAN task view "Psychometrics" (Mair, 2019). The book covers 14 chapters, and in the following review, I classify the chapters into core, broadened, and uncommon psychometrics and provide a discussion of the contents. In Table 1, the titles and the $\mathrm{R}$ packages used in the chapters are displayed.
\end{abstract}

\section{OPEN ACCESS}

Edited and reviewed by:

Stéphane Bouchard,

University of Quebec in

Outaouais, Canada

*Correspondence:

Alexander Robitzsch

robitzsch@leibniz-ipn.de

Specialty section: This article was submitted to Quantitative Psychology and Measurement,

a section of the journal

Frontiers in Psychology

Received: 17 February 2020

Accepted: 13 March 2020

Published: 15 April 2020

Citation:

Robitzsch A (2020) Book Review:

Modern Psychometrics With R.

Front. Psychol. 11:606.

doi: 10.3389/fpsyg.2020.00606

\section{CORE PSYCHOMETRICS (CHAPTERS 1-5; 174 PAGES)}

In Chapter 1, the basics of classical test theory (CTT) and reliability measures are discussed, and the generalizability theory is also introduced. Chapter 2 provides an overview of exploratory and confirmatory factor analysis (CFA), as well as briefly discussing multiple-group and multilevel CFA models. Chapter 3 describes structural equation models (SEMs). Before introducing SEMs in their general form, the chapter starts with path models and (moderated) mediation models. In Chapter 4, unidimensional item response theory (IRT) models, as well as multidimensional exploratory and confirmatory IRT models, are described. The chapter also discusses differential item functioning techniques (i.e., logistic regression and tree methods). In Chapter 5, the analysis of pairwise comparisons and ranking data is considered. As an extension, in Chapters 2 to 5, longitudinal and Bayesian variants of CFA, SEM, and IRT models are discussed. In the first part of the book, the use of regularization techniques (e.g., employing the lasso penalty) is addressed only for the Bradley-Terry model in Chapter 5 (and later in Chapter 6) but could also be a valuable extension for CFA, SEM, and IRT models (see, for example, Jacobucci et al., 2016). It is my opinion that equating and linking techniques should also be recognized as part of core psychometrics (González and Wiberg, 2017).

\section{BROADENED PSYCHOMETRICS (CHAPTERS 11-13; 95 PAGES)}

In Chapter 11, network models in which the objects can be either persons or variables are discussed, and Bayesian networks are introduced. An extension to latent variable network models (Epskamp et al., 2018) would be helpful and could be considered in a future edition of the book. 
TABLE 1 | Table of contents and R packages used in Mair (2018).

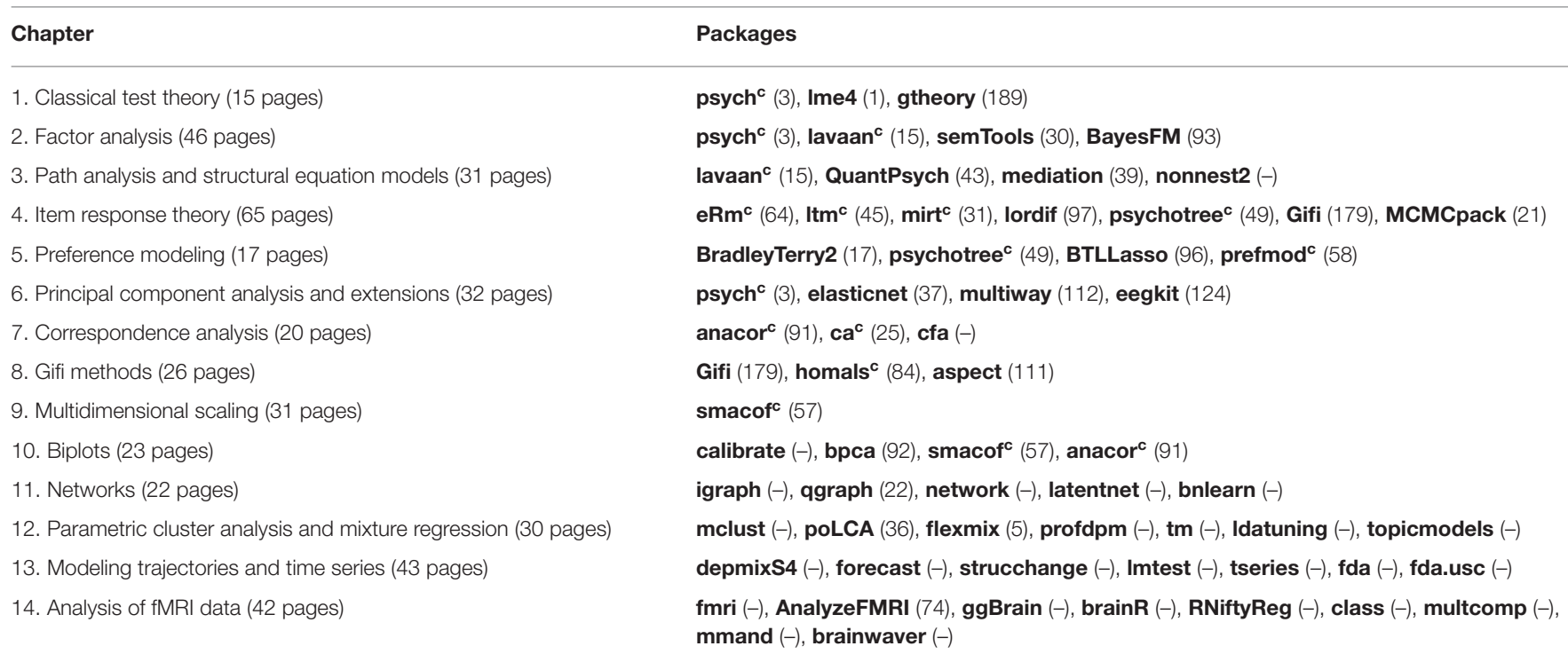

${ }^{c}=R$ package contained in CRAN task view "Psychometrics" (CTVP; Mair, 2019). Numbers in parentheses after R packages are download ranks from the CRAN server in 2019 from the $221 R$ packages listed in the CTVP. The download statistics were obtained using the R package cranlogs (Csárdi, 2019). A hyphen ("-") indicates that the respective package is not included in the CTVP list of $R$ packages.

Chapter 12 explains model-based clustering approaches, mainly mixture regression, latent class analysis, and Dirichlet process clustering. Although mixture latent variable models are popular in applied research, they are not mentioned in this chapter. Chapter 13 discusses techniques for longitudinal data: hidden Markov models, single-subject time series, and functional data analysis. Readers could also find developments in multiple-subject (dynamic) time series models (mainly in the software Mplus) and in continuous time models (Driver et al., 2017) interesting. In my view, broadened psychometrics should also include meta-analysis (Viechtbauer, 2010; Cheung, 2015).

\section{UNCOMMON PSYCHOMETRICS (CHAPTERS 6-10, CHAPTER 14; 174 PAGES)}

Chapter 6 starts with a detailed treatment of principal component analysis. It also introduces multiway analysis and independent component analysis. In Chapter 7, simple and multiple correspondence analysis and configural frequency analysis are explained. Chapter 8 focuses on a collection of exploratory techniques that are labeled as Gifi methods. Chapters 9 and 10 give an overview of multidimensional scaling and biplot techniques, respectively. Chapter 14 explains techniques for analyzing fMRI data that are seldom found in the psychometric research literature. The techniques described in Chapters 7 to 10 are also not frequently found in psychometric and applied research, maybe due to their mainly exploratory nature.

\section{CLASSICAL, MODERN, AND FUTURE PSYCHOMETRICS}

To sum up, the book is a valuable and well-structured resource that forms links to a variety of $\mathrm{R}$ packages and, therefore, differs in content and depth from many other psychometrics books (e.g., Beaujean, 2014; Desjardins and Bulut, 2018; Paek and Cole, 2019). Given the variety of R packages used, I would have preferred the author to consistently use the package :: function notation to write the $\mathrm{R}$ function throughout the book ${ }^{1}$. In my opinion, a contemporary psychometrics book should put more emphasis on CTT (Nunnally and Bernstein, 1994; Meyer, 2010), CFA, and IRT models and I would like it to be more focused on design-based reliability (CTT) instead of model-based reliability (CFA and IRT models) ${ }^{2}$. The division of the book into core, broadened, and uncommon psychometrics makes it unique. However, this means that it cannot be the first choice for a companion book in an ordinary psychometrics course.

It is impressive how the $\mathrm{R}$ software has evolved in the last 10 years (see, for example, the lavaan and mirt packages; Chalmers,

\footnotetext{
${ }^{1}$ If this notation is not used, function conflicts could occur if $\mathrm{R}$ functions with the same name occur in different (loaded) R packages. For example, Cronbach's alpha is available in several packages with a function name alpha (psych, psychometric, coefficientalpha, plspm, epiDisplay).Therefore, it makes sense to explicitly write psych::alpha if the function from the psych package is requested. Another critical example is the function name cfa that is used in the lavaan and sem package (for confirmatory factor analysis) as well as in the cfa package (for configural frequency analysis).

${ }^{2}$ In fact, as opposed what is frequently claimed in recent literature, CTT or generalizability theory have fewer assumptions than CFA or IRT because items are treated as random (i.e., exchangeable) in the former case while they are considered as fixed in the latter case (see Brennan, 2011).
} 
2012; Rosseel, 2012). Given the rapid development of R packages, a new edition of this book would certainly be needed again in 10 years. In my opinion, $\mathrm{R}$ has made impressive progress, but $\mathrm{R}$ packages can still not fully compete with flexible and highquality commercial software programs such as LatentGold or Mplus. The future will show whether equally flexible alternative open-source R packages have been developed. Maybe generalpurpose software (like BUGS and its successors: Lunn et al.,

\section{REFERENCES}

Beaujean, A. A. (2014). Latent Variable Modeling Using R: A Step-by-Step Guide. New York, NY: Routledge. doi: 10.4324/9781315869780

Brennan, R. L. (2011). Generalizability theory and classical test theory. Appl. Meas. Educ. 24, 1-21. doi: 10.1080/08957347.2011.532417

Carpenter, B., Gelman, A., Hoffman, M. D., Lee, D., Goodrich, B., Betancourt, M., et al. (2017). Stan: a probabilistic programming language. J. Stat. Softw. 76, 1-32. doi: 10.18637/jss.v076.i01

Chalmers, R. P. (2012). mirt: a multidimensional item response theory package for the R environment. J. Stat. Softw. 48, 1-29. doi: 10.18637/jss.v048.i06

Cheung, M. W. L. (2015). metaSEM: an R package for metaanalysis using structural equation modeling. Front. Psychol. 5:1521. doi: 10.3389/fpsyg.2014.01521

Csárdi, G. (2019). cranlogs: Download Logs From the 'RStudio' 'CRAN' Mirror. $\mathrm{R}$ package version 2.1.1. Available online at: https://CRAN.R-project.org/ package $=$ cranlogs

Desjardins, C. D., and Bulut, O. (2018). Handbook of Educational Measurement and Psychometrics Using R. Boca Raton, FL: Chapman \& Hall. doi: 10.1201/b20498

Driver, C. C., Oud, J. H., and Voelkle, M. C. (2017). Continuous time structural equation modeling with R package ctsem. J. Stat. Softw. 77, 1-35. doi: 10.18637/jss.v077.i05

Epskamp, S., Maris, G., Waldorp, L. J., and Borsboom, D. (2018). "Network psychometrics," in The Wiley Handbook of Psychometric Testing: A Multidisciplinary Reference on Survey, Scale and Test Development, eds P. Irwing, T. Booth, and D. J. Hughes (New York, NY: Wiley), 953-986. doi: $10.1002 / 9781118489772 . \operatorname{ch} 30$

González, J., and Wiberg, M. (2017). Applying Test Equating Methods. Using R. Cham: Springer. doi: 10.1007/978-3-319-5 1824-4

Jacobucci, R., Grimm, K. J., and McArdle, J. J. (2016). Regularized structural equation modeling. Struct. Equat. Model. 23, 555-566. doi: 10.1080/10705511.2016.1154793

Kristensen, K., Nielsen, A., Berg, C. W., Skaug, H., and Bell, B. M., (2016). TMB: automatic differentiation and Laplace approximation. J. Stat. Softw. 70, 1-21. doi: $10.18637 /$ jss.v070.i05
2009; OpenMx: Neale et al., 2016; Stan: Carpenter et al., 2017; or TMB: Kristensen et al., 2016) might become more widespread in applied research in the future.

\section{AUTHOR CONTRIBUTIONS}

AR was responsible for the writing.

Lunn, D., Spiegelhalter, D., Thomas, A., and Best, N. (2009). The BUGS project: evolution, critique and future directions. Stat. Med. 28, 3049-3067. doi: $10.1002 / \operatorname{sim} .3680$

Mair, P. (2018). Modern Psychometrics With R. Cham: Springer. doi: 10.1007/978-3-319-93177-7

Mair, P. (2019). CRAN Task View: Psychometrics. Version 2019-12-13. Available online at: http://CRAN.R-project.org/view=Psychometrics

Meyer, J. P. (2010). Understanding Measurement: Reliability. Oxford: Oxford University Press.

Neale, M. C., Hunter, M. D., Pritikin, J. N., Zahery, M., Brick, T. R., Kirkpatrick, R. M., et al. (2016). OpenMx 2.0: extended structural equation and statistical modeling. Psychometrika 81, 535-549. doi: 10.1007/s11336-0149435-8

Nunnally, J. C., and Bernstein, I. H. (1994). Psychometric Theory. New York, NY: McGraw-Hill.

Paek, I., and Cole, I. (2019). Using $R$ for Item Response Theory Applications. New York, NY: Routledge. doi: 10.4324/97813510 08167

R Core Team (2020). R: A Language and Environment for Statistical Computing. Vienna: R Foundation for Statistical Computing. Available online at: https:// www.R-project.org/

Rosseel, Y. (2012). lavaan: an R package for structural equation modeling. J. Stat. Soft. 48, 1-36. doi: 10.18637/jss.v048.i02

Viechtbauer, W. (2010). Conducting meta-analyses in $\mathrm{R}$ with the metafor package. J. Stat. Softw. 36, 1-48. doi: 10.18637/jss.v03 $6 . \mathrm{i} 03$

Conflict of Interest: The author declares that the research was conducted in the absence of any commercial or financial relationships that could be construed as a potential conflict of interest.

Copyright (c) 2020 Robitzsch. This is an open-access article distributed under the terms of the Creative Commons Attribution License (CC BY). The use, distribution or reproduction in other forums is permitted, provided the original author(s) and the copyright owner(s) are credited and that the original publication in this journal is cited, in accordance with accepted academic practice. No use, distribution or reproduction is permitted which does not comply with these terms. 